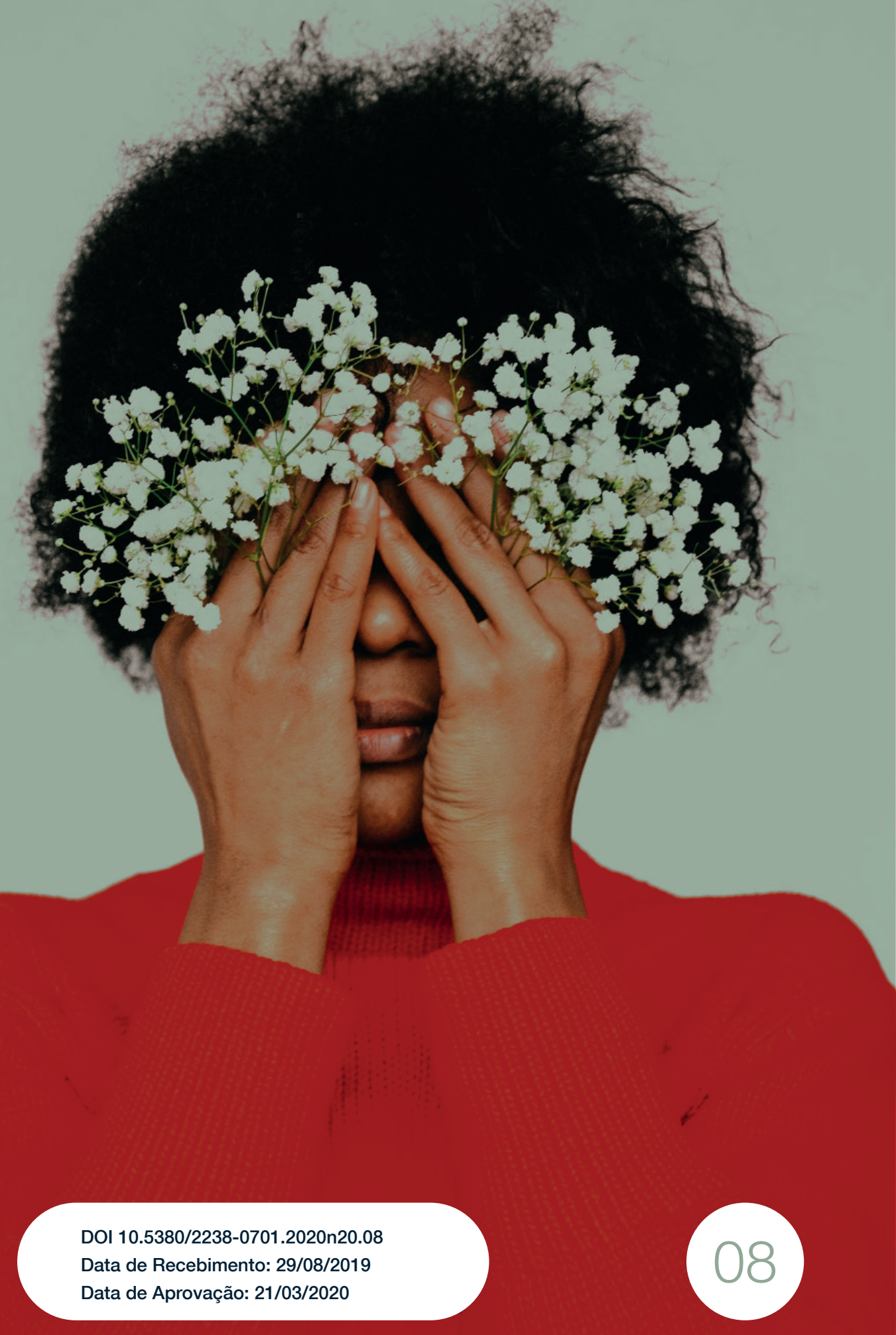


Corpo, mídia e subjetividade: lutas por reconhecimento na trajetória da cantora 


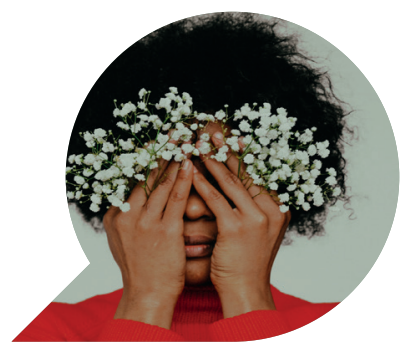

\section{Corpo, mídia e subjetividade: lutas por visibilidade na trajetória da cantora Ludmilla $^{1}$}

Body, media and subjectivity: struggles for visibility in the trajectory of singer Ludmilla

Cuerpo, medios y subjetividad: Iuchas por visibilidad en la trayectoria de la cantante Ludmilla

DARIANE ARANTES ${ }^{2}$

HADRIEL THEODORO ${ }^{3}$

Resumo: O objetivo deste artigo é refletir sobre o papel da mídia nas (re)significações do corpo das mulheres negras, a partir do recente processo de transição capilar da cantora Ludmilla. Como direcionamento teórico-metodológico, nos pautamos na análise de narrativas midiáticas proposta por Omar Ríncon, tendo por objeto empírico a campanha publicitária \#todecacho (Salon Line), de 2017, protagonizada por Ludmilla. Como principal resultado, verifi-

1 Uma versão preliminar deste estudo foi apresentada no GP Comunicação e Culturas Urbanas, durante o XVII Encontro dos Grupos de Pesquisas em Comunicação do 40 Congresso Brasileiro de Ciências da Comunicação - Intercom 2017, realizado em Curitiba (PR).

2 Mestre pelo Programa de Pós Graduação em Comunicação e Práticas do Consumo da Escola Superior de Propaganda e Marketing - ESPM e doutoranda na mesma instituição. Integra o grupo de pesquisa Juvenália, vinculado ao CNPQ. Bolsista Capes.

3 Mestre em Comunicação e Práticas de Consumo pela Escola Superior de Propaganda e Marketing (ESPM-SP) e doutorando na mesma instituição (bolsista FAPESP). Graduado em Comunicação Social pela Escola de Comunicações e Artes (ECA-USP) e em Letras pela Faculdade de Filosofia, Letras e Ciências Humanas (FFLCH-USP). E-mail: hgtheodoro@gmail.com 
camos que o posicionamento da cantora pode ser compreendido como um ato político de resistência frente a padrões de beleza hegemônicos, que primam por uma estética de branquitude.

Palavras-chave: Corpo; Negritude; Mídia; Visibilidade; Subjetividade.

Abstract: The objective of this article is to reflect on the role of the media in the (re)meanings of black women's bodies, based on Ludmilla's recent capillary transition process. As a theoretical-methodological approach, we are guided by the analysis of media narratives proposed by Omar Ríncon, with the advertising campaign \#todecacho (Salon Line), of 2017, as the empirical object, starring Brazilian singer Ludmilla. As a main result, we found that the position of the singer can be understood as a political act of resistance against hegemonic beauty standards, which stand out for a whiteness aesthetic.

Keywords: Body; Blackness; Media; Visibility; Subjectivity.

Resumen: El propósito de este artículo es reflexionar sobre el papel de los medios en las (re)significaciónes del cuerpo de las mujeres negras, basado en el reciente proceso de transición capilar de la cantante Ludmilla. Como enfoque teórico-metodológico, guiamos por el análisis de las narrativas mediáticas propuestas por Omar Ríncon, teniendo como objeto empírico la campaña publicitaria \#todecacho (Salon Line), en 2017, dirigida por Ludmilla. Como resultado principal, descubrimos que la posición del cantante puede entenderse como un acto político de resistencia frente a los estándares de belleza hegemónicos, que destacan por una estética de blancura.

Palabras clave: Cuerpo; Negritud; Medios; Visibilidad; Subjetividad. 


\section{Introdução ${ }^{4}$}

A partir de uma articulação teórica entre comunicação e estudos da cultura, buscamos refletir neste artigo sobre a dimensão física e estética do corpo. Na contemporaneidade, a dimensão corpórea de nossa existência passa a adquirir centralidade nas discussões pertinentes à mídia, assumindo papel de extrema importância na constituição das identidades e nos processos de pertencimento e distinção (HOFF, 2008). Por meio de sua produção imagética, a mídia se institui como uma articuladora das representações corpóreas, ao legitimar certos modos de sociabilidade, a partir de suas prescrições de como viver e se relacionar em sociedade.

Levando isso em consideração, estabelecemos como problemática a possibilidade de negociação de sentidos proveniente da estética, pautando-nos em um importante elemento material e simbólico de nossa expressão identitária: o cabelo. Para tanto, consideramos especificamente a experiência de transição capilar ${ }^{5}$, pois dela emergem sentidos ligados aos corpos negros, englobando estereótipos, estigmas e formas de exclusões, mas também possíveis sentidos de (re)significação e (re) existência.

No presente trabalho, trazemos a cantora Ludmilla, figura de destaque no cenário musical brasileiro, para o centro da discussão, por entender que sua trajetória de vida contém um conjunto de experiências no tocante a políticas de visibilidade da mulher negra. De maneira a delimitar o objeto empírico do estudo, escolhemos a campanha publicitária \#todecacho6 ${ }^{6}$ de 2017, protagonizada pela cantora, em parceria

\footnotetext{
4 As reflexões e análises realizadas nesse artigo são decorrentes da pesquisa de mestrado "Celebrando nossos corpos, encrespando nossos fios: as narrativas de transição capilar como políticas de visibilidade em mulheres negras", desenvolvida no Programa em Comunicação e Práticas de Consumo da Escola Superior de Propaganda e Marketing (PPGCOM-ESPM), sob orientação da Prof. ${ }^{a}$ Dr. ${ }^{a}$ Rose de Melo Rocha e financiamento da Coordenação de Aperfeiçoamento de Pessoal de Nível Superior (CAPES). A investigação articula as dinâmicas entre comunicação e culturas do consumo no debate centrado nas visibilidades sociais que emanam das vivências midiáticas de mulheres negras, objetivando entender como os fluxos identitários e culturais que emergem dessas experiências autobiográficas midiatizadas dialogam com realidades sociais e contextos culturais atrelados às subjetividades, disputas simbólicas e imaginários, em um contexto permeado por lógicas de branqueamento e pelo mito da democracia racial.

5 Processo que consiste em abandonar a utilização de produtos químicos alisadores e deixar os fios crescerem naturalmente, cortando toda a parte alisada.

6 "\#Todecacho" é o nome de uma linha de cosméticos comercializada pela empresa brasileira Salon Line, sendo voltada para mulheres de cabelos cacheados e crespos. Em 2017, ano de seu lança-
} 
com a marca de cosméticos brasileira Salon Line. Nela, a temática da transição capilar é posta em cena, permitindo analisar, a partir da forma como Ludmilla mobiliza tais sentidos, como narrativas da diferença são incorporadas e negociadas.

Como direcionamento teórico-metodológico, nos valemos da análise de narrativas midiáticas proposta por Omar Ríncon (2006). Segundo o autor, as narrativas midiáticas se constituem como relatos que adquirem sentido na medida em que são narrados. O ato de narrar é, portanto, uma forma de nos constituirmos enquanto sujeitos e também de compreendermos a realidade à nossa volta. Construídas nos espaços midiáticos, tais narrativas são ao mesmo tempo produtos e dispositivos de interpretação das culturas midiáticas (RíNCON, 2006). Assim, uma campanha publicitária como a protagonizada por Ludmilla se configura como uma forma de narrar que mobiliza um complexo conjunto de sentidos - socioculturalmente criados e compartilhados. O foco de nossa observação e análise se detém, portanto, nas apropriações e nas estratégias de visibilidade midiática mobilizadas a partir da experiência de transição capilar da cantora.

Corpo negro e mídia: disputas de sentido, representações e invisibilidades

A formação subjetiva e identitária de um indivíduo está inscrita em seu corpo e, segundo Campelo (1997), é visível através das informações que dele fluem. Para apreender essas corporalidades, há de se levar em consideração não apenas sua perspectiva física ou biológica, mas também os sentidos sociais e culturais que as perpassam. O corpo humano é atravessado por construções simbólicas de ordem religiosa, familiar, estética, midiática etc. Assim, converte-se em um repositório de ideologias presentes na cultura em que se insere. Isso significa que sua aparência, como coloca Nogueira (1999), está sujeita a diversas classificações em relação ao conjunto de atributos que caracterizam a imagem dos indivíduos de determinado grupo social, em termos do espectro de tipificações existente. O corpo está, portanto, suscetível a significações e atribuições de valor.

Baitello (2010) enxerga que o recente espraiamento das mídias e a centralidade por elas assumidas na vida cotidiana provocam alterações 
em nossa ideia de corpo. Sendo assim, a concepção de corpo passa a se ver expandida, fragmentada, (re)composta em permanência, (re) significada, sempre em disputa: converte-se em um verdadeiro campo de batalhas sígnico, onde também estão implicadas diversas formas de subjetividade e construções identitárias.

Nesse contexto, Kellner (2001, p. 11) compreende a cultura da mídia como sendo o território onde essas de disputas de sentido se dão "por meio de imagens, discursos, mitos, espetáculos e representações". O autor, ao pensar as produções televisivas voltadas ao entretenimento (e igualmente as peças publicitárias), entende que tais narrativas fornecem modelos identitários, solucionam contradições sociais e enaltecem a ordem social vigente. Dessa forma, ele compreende que a cultura midiática ocupa e transforma o cotidiano ao adquirir uma função modelar de veicular e, por vezes, reiterar lutas e discursos sociais (KELLNER, 2001).

Hoff (2008), por sua vez, assinala que as representações midiáticas acerca do corpo implicam em uma realidade editada, em que determinados padrões corporais são privilegiados e apresentados como "belos" ou como ideal a ser atingido. Enquanto isso, os que se distanciam dessas características se tornam descartáveis nas representações midiáticas, ou são visibilizados de maneira pejorativa.

Em uma sociedade como a brasileira, marcada ao longo dos séculos pela colonização, escravidão e por processos de branqueamento, os elementos corpóreos se destacam como forma de analisar as imposições e estigmas a que estão sujeitos os corpos negros. Isto porque, aqui, o racismo também opera em uma ordem fenotípica - beneficiando pessoas de pele clara e traços finos. Nesse contexto, as mídias, atreladas aos processos de agenciamento, fomentam a disseminação de sentidos referentes a uma valorização da branquitude, existente desde o período escravocrata (QUINTÃO, 2013).

Na década de 1920, por exemplo, já era notável em propagandas um predomínio das representações femininas fazendo referência a padrões estéticos europeus (HOOF, 2008). Essa hierarquização pautada por traços fenotípicos foi atribuindo uma série de sentidos a tais representações midiáticas, relacionando-se às "marcas corporais" diretamente percebidas e performadas pelos sujeitos. Elas se associam diretamente à cor da pele, ao tipo de cabelo, ao formato do nariz etc.

Logo, as produções midiáticas nos auxiliam a pensar acerca das 
significações que agregam concepções negativas a elementos corpóreos atribuídos à negritude, em especial nas discussões acerca da representação da mulher negra, constantemente vinculada a aspectos pejorativos e subalternizantes (ARAUJO, 2006). Isso acaba por reverberar muitos dos sentidos instituídos em um passado escravocrata.

Além da publicidade, as telenovelas também são importantes produtos culturais que influenciam a forma como a imagem da negritude é percebida e retratada no Brasil. Araújo (2006) aponta que a estética do branqueamento se tornou referência na produção de telenovelas no país. As representações da mulher negra no cinema brasileiro não costumam diferir muito, o que acarreta uma naturalização de estereótipos e de uma invisibilidade estrutural (FERREIRA, 2018).

Nas produções midiáticas brasileiras, a estética negra sempre caminhou paralelamente ao racismo e a padrões fenotípicos eurocêntricos, como o cabelo liso, disseminado em representações midiáticas como ideal a ser seguido, influenciando milhares de mulheres a abdicarem de suas características raciais e adotarem modelos hegemônicos como forma de disfarçar sua "negritude". Para bell hooks (2014), os processos de alisamento consistem em uma pauta de muita relevância sobre as discussões raciais, em uma sociedade de supremacia branca em que mulheres negras crescem inseguras de seu valor.

Segundo Sant'Anna (2018), no início do século XX já se podia perceber no discurso publicitário e na imprensa um fomento aos métodos de alisamento. "O Cabelisador", produto com o intuito de alisar os fios, estampava muitas propagandas e era bastante popular entre as mulheres negras. Antes de sua invenção, contudo, receitas caseiras e rituais, como passar os cabelos a ferro, já eram utilizados como estratégias de alisamento.

Nesse momento em que a publicidade promovia um ideal de beleza eurocêntrico, "O Cabelisador" surgia como uma "invenção incrível" para resolver um dos motivos de desalento das mulheres negras: a textura crespa. A representação do cabelo crespo como algo que deveria ser suprimido, reforça um ideal de beleza pautado na estética dos fios lisos, associado a sentidos como "beleza", "elegância" e "modernidade". Nos discursos publicitários, ter o cabelo alisado passou a ser sinônimo de "mais apresentável socialmente". Para bell hooks, essa lógica, sempre afetou a percepção que as mulheres negras possuem de si mesmas: 
Aos olhos de muita gente branca e outras não negras, o black power parece palha de aço ou um casco. As respostas aos estilos de penteado naturais usados por mulheres negras revelam comumente como o nosso cabelo é percebido na cultura branca: não só como feio, como também atemorizante. Nós tendemos a interiorizar esse medo. O grau em que nos sentimos cômodas com o nosso cabelo reflete os nossos sentimentos gerais sobre o nosso corpo (HOOKS, 2014, n. p.).

Assim, ao mesmo tempo em que as representações publicitárias celebravam e promoviam a estética dos fios lisos, advindos dos padrões eurocêntricos, disseminavam sentidos estereotipados e negativos acerca dos cabelos crespos. Essas representações, que, ao mesmo tempo em que valorizavam o cabelo liso, discriminavam os fios afro, tinham como intuito "marcar a diferença", promovendo o entendimento disciplinado de que as diferenças são permanentes e naturais - quando, na verdade, "eram naturalizadas por um discurso ideológico e publicidade visual editadas com esse objetivo" (SILVA, 2016 apud HALL, 2010, p. 427).

Ao pensar as experiências cotidianas de racismo e seus impactos na subjetividade, Grada Kilomba (2019) nos lembra que os sentidos derivados de narrativas colonialistas, gerados e reiterados nos espaços comuns, incluindo o das produções midiáticas, não dizem respeito ao "sujeito negro", mas a fantasias que povoam o imaginário branco sobre o que a negritude deveria ser. Nesse sentido, a população negra aprende a conviver diariamente com imagens irreais e nada gratificantes de si mesmos, o que pode ser uma experiência dolorosa e traumática.

Kilomba (2019) aproxima a estética aos mecanismos que dão sentido às formas de construção e representação do "Outro", focando sua exposição nas variadas formas de silenciamento que foram impostas aos negros escravizados. Dessa forma, o "outro" é construído como o antagonista do "eu", transformando-se na representação mental daquilo que o sujeito branco não deseja ser. Ao "outro" é atribuído a indolência, a agressividade, a malícia, a feiura, a inconformidade, "permitindo à branquitude olhar para si como moralmente ideal, decente, civilizada e majestosamente generosa" (KILOMBA, 2019, p. 73).

Stuart Hall (2003), ao reconhecer na mídia um papel de mediação cultural, por gerar e transmitir toda uma iconografia identitária, aproxima esse debate de seu sentido político, ao refletir sobre as disputas 
de poder e sobre os fluxos diaspóricos que trazem a alteridade, historicamente silenciada, para a cena hegemônica. Nesta perspectiva, as produções midiáticas se tornam espaços privilegiados para pensar os tensionamentos e conflitos que se formam em um processo de globalização e multiculturalismo que desmantela os conceitos clássicos de identidade.

Atualmente, é possível perceber que a comunicação em rede tem favorecido um aumento no número de compartilhamento das narrativas midiáticas sobre a estética negra. Após períodos de transformação nas formas de uso do cabelo afro, que enfatizavam principalmente processos químicos como alisamento e relaxamento, nos últimos anos, movimentos pela valorização das texturas crespas e cacheadas, atreladas a um discurso de aceitação, têm se tornado cada vez mais frequentes.

Essas narrativas de enaltecimento das texturas crespas e cacheadas têm adquirido espaço significativo em sites de rede social, como a plataforma digital de compartilhamento de vídeos YouTube. Elas trazem a presença da mulher negra figurando como protagonista, algo pouco presente em mídias tradicionais, como a publicidade, a televisão e o cinema. Ao mesmo tempo, tem surgido nos espaços midiáticos, em pautas televisivas e, principalmente, em anúncios e propagandas, narrativas que incorporam esse enaltecimento dos "cachos". Elas dialogam com o movimento de aceitação difundido em sites de redes sociais, a partir do compartilhamento de relatos de experiências de mulheres negras com os próprios cabelos.

Nesse novo cenário, como resultado de uma política cultural da diferença, de produção de novas identidades e da aparição de novos sujeitos no cenário político cultural, que adentram os espaços dominantes (HALL, 2003), a estética se transforma em um campo de disputas de sentido. Logo, os espaços midiáticos tomam protagonismo ao visibilizar pautas minoritárias, transformando-as em ações políticas. Da discussão sobre representatividade midiática, por exemplo, a invisibilidade de atores negros em telenovelas, telejornais, filmes e demais produções audiovisuais, advêm temáticas fundamentais para se questionar a exclusão social de afrodescendentes e o papel da cultura midiática na perpetuação do racismo.

É válido ressaltar que essas narrativas estão longe de expressar um total rompimento com padrões estéticos eurocêntricos, ainda predomi- 
nantes nas representações midiáticas. Contudo, elas nos permitem verificar possíveis deslocamentos de sentido acerca de como a imagem do negro vem sendo retratada na mídia, assim como observar seus impactos nas identidades de mulheres negras.

Desta forma, refletir sobre essas narrativas de mulheres negras compartilhadas em rede, atreladas a representações midiáticas da estética negra, constitui-se como uma questão privilegiada para pensar a comunicação a partir do prisma da diversidade. Também é de suma importância para tensionar suas possíveis implicações no empoderamento de mulheres negras, a partir de estratégias de "descolonização estética" - neste caso, tendo como princípios o abandono dos processos de alisamento e a valorização das texturas crespas.

\section{A transição capilar em cena: o caso de Ludmilla}

"Chegou a hora de ser eu mesma", declarou a cantora Ludmilla ao revelar, em abril de 2017, que "assumiria" seu cabelo natural. A palavra "assumir" adquire um sentido interessante nesta afirmação, pois o que leva alguém a querer assumir algo que, de fato, possui (no caso, os cabelos crespos)? Ou, invertendo o raciocínio, o que leva alguém a decidir ocultar determinado traço capilar, como a aparência e textura dos fios de cabelo? Para ponderarmos sobre essas razões e os conflitos que englobam, é necessário considerar a trajetória da cantora enquanto mulher negra, atentando para as significações do que se considera "cabelo bom" ou "cabelo ruim" — termos que, em si mesmos, refletem a história do racismo e da cultura do branqueamento em nossa sociedade e cultura.

Ludmila Oliveira da Silva, conhecida nacionalmente pelo nome artístico "Ludmilla", nasceu e foi criada no subúrbio da cidade do Rio de Janeiro. Despontou no cenário pop brasileiro com um vídeo postado no YouTube, que alcançou recordes de visualizações em 2012. Com uma personalidade marcada pelo carisma e irreverência, logo se tornou popular. Em 2014, solidificou sua carreira como cantora ao assinar contrato com a gravadora Warner Music e lançar seu primeiro álbum. Com reper-

7 Disponivel em: <https://f5.folha.uol.com.br/celebridades/2017/04/chegou-a-hora-de-ser-eu-mesma-diz-ludmilla-sobre-abandonar-cabelos-lisos.shtml>. Acesso em: 27 fev. 2020. 
cussão midiática positiva e expressivo número de vendas, passou a ser tratada como celebridade pelos meios de comunicação.

Em 2019, recebeu o Prêmio Multishow de Música Brasileira na categoria de "melhor cantora"8. Com cerca de oito anos de carreira, Ludmilla se mantém como figura recorrente na mídia nacional, com participação em programas de TV e novelas, além de ter diversas músicas nas paradas de sucesso. Ainda em 2019, a cantora abriu negociações para assinatura de contrato com a gravadora americana Roc Nation, do cantor Jay-Z, que ficará encarregada do gerenciamento de sua carreira internacional.

A ascensão e o sucesso da cantora são constantemente marcados por episódios de preconceito, já tendo sido alvo publicamente de racismo em várias ocasiões. Uma delas, que adquiriu bastante repercussão, ocorreu em fevereiro de 2016, durante uma transmissão ao vivo em um programa da Rede TV. Enquanto comentava os desfiles das Escolas de Samba do Rio de Janeiro, a apresentadora e empresária Val Marchiori criticou o cabelo de Ludmilla, com os dizeres: "Esse cabelo dela está parecendo um bombril". Ao estabelecer uma analogia à figura de uma lã de aço, o termo "bombril" foi utilizado de maneira pejorativa por Val para conceituar o cabelo crespo de Ludmilla.

Ludmilla passou a alisar o cabelo ainda muito jovem, com cerca de sete anos de idade. Em um vídeo para o pré-lançamento da campanha publicitária da Salon Line, publicado em 28 de abril de 2017 no canal da marca no YouTube, ela compartilha um pouco dessas memórias: "Eu não lembrava mais como era o meu cabelo, alisava desde a primeira série. Eu fui criada ali no meio das pessoas achando que cabelo crespo, cacheado, era a coisa mais feia do mundo e que [ter o cabelo assim] não era normal. Então por isso eu queria alisar, passar formol"9. Sua narrativa reflete a de muitas mulheres negras brasileiras quanto à dificuldade da autoaceitação, ao preconceito e às tentativas de se aproximar de um padrão estético que as torne menos suscetíveis a experiências racistas.

Segundo Omar Ríncon (2006), ao narrarmos, criamos "mundos possíveis". Nesse sentido, a mídia se configura como espaço de "reconhecimento", ao se tornar território da disputa do visível, do narrável

8 Prêmio Multishow 2019. Disponível em: <https://wnw.youtube.com/watch?v=ve85hjAbL5E>. Acesso em: 10 mar. 2020

9 "Ludmilla conta sobre sua transição capilar". Disponível em: <https://www.youtube.com/watch?v=VLlpw90-g2Y>. Acesso em: 20 fev. 2020. 
e do reconhecido (RíNCON, 2006). Na narrativa de Ludmilla, o cabelo - entendido como elemento corpóreo utilizado para exibir não apenas gosto pessoal, mas pertencimento, filiação a uma causa ou até mesmo um ato político - é trazido para o centro do debate sobre os estigmas que atravessam os corpos negros, ainda constantemente vistos como corpos exóticos, a serem explorados e modificados para se enquadrarem a padrões estéticos eurocêntricos. É um exemplo que evidencia a manutenção de relações conflituosas das mulheres negras com padrões de beleza hegemônicos.

Contudo, ao observar o relato da cantora sobre sua transição capilar, podemos notar que questões como o racismo ou padrões de beleza excludentes na publicidade não são problematizados. Em nenhum momento sua experiência é associada a uma coletividade ou ligada a um traço de cor - apesar de, por se tratar do relato de uma mulher negra, ficar de certo modo implícito.

Em seu depoimento, é atribuída à marca Salon Line o fator motivacional que a incentivou a passar por tal transformação:

Eu tenho muitas amigas que têm o cabelo cacheado e elas usam os produtos da Salon Line e falaram "Lud, se você vai cuidar do cabelo, usa isso aqui, porque é muito bom". Aí, quando conheci os produtos e comecei a usar, me encorajei, cortei o meu cabelo, cortei muito baixinho mesmo, comecei a usar Salon Line e criei coragem de entrar na transição capilar. ${ }^{10}$

Figura 1: Relatando a transição

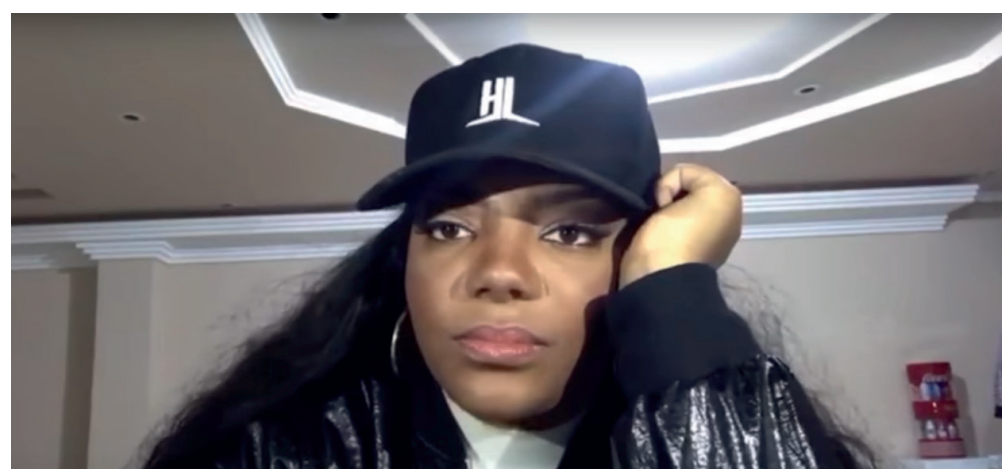

Fonte: <https://www.youtube.com/watch?v=VLlpw90-g2Y>.

10 "Ludmilla conta sobre sua transição capilar". Disponível em: <https://uww.youtube.com/watch?v=VLlpw90-g2Y>. Acesso em: 20 fev. 2020. 
A divulgação do vídeo foi concomitante ao anúncio de que Ludmilla havia sido contratada pela marca, evidenciando que, para além de uma experiencia pessoal, sua transição capilar foi também utilizada como estratégia publicitária em parceria com a Salon Line. A marca, na época, se reposicionava no mercado de cosméticos, com produtos voltados especificamente para cabelos crespos e cacheados em suas texturas naturais, após quase 18 anos comercializando produtos voltados para o alisamento capilar.

Tais fatores evidenciam as ambivalências e ambiguidades próprias da indústria midiática, que atua enquanto território de construção de significações e confrontações da alteridade e de disputas de sentido (RíNCON, 2006). Portanto, mais do que os conteúdos, é necessário também olhar para a comunicabilidade das formas de narrar que são mobilizadas. No caso de Ludmilla, há um relato pessoal inserido na campanha publicitária de uma marca que se dedica a vender produtos cosméticos - o que não invalida os sentidos de racismo e exclusão e as ressignificações acerca do cabelo crespo que são propostas.

Assim, ao assumir os cachos, passando pelo processo de transição capilar, a cantora se insere em um contexto de reconhecimento da diferença, permitindo visualizar um caráter político a partir do estético. Como podemos verificar, o processo de modificação capilar envolve a (re)significação do corpo negro, que deixa de ser um "corpo inconforme" para se transformar em um "corpo a ser celebrado". Em sua narrativa, ao afirmar poder "ser diferente", Ludmilla repercute esse símbolo da resistência, que envolve o reconhecimento do valor e da beleza da própria ancestralidade africana, marcada por processos de invisibilidade e subjugação. Isso corrobora a ideia de Ríncon (2006) de que as narrativas midiáticas nos permitem debater o comum, o banal, em sua dimensão política.

A campanha publicitária, além do relato pessoal da cantora sobre o seu processo de transição capilar, contou com um comercial, em formato de videoclipe, estrelado por Ludmilla e lançado em 25 de abril de 2017, também no canal da Salon Line no YouTube. A produção audiovisual foi desenvolvida pela agência Brancozulu ${ }^{11}$ e dirigido por Kond-

11 A Brancozulu é uma agência de comunicação paulistana que tem como foco empresas de médio porte. 
zilla $^{12}$. Com mais de 23 milhões de visualizações no YouTube ${ }^{13}$, o videoclipe tem como enredo a celebração dos cabelos crespos e cacheados em um cenário de uma grande festa, com luzes, danças e roupas cheias de brilho.

No centro da cena aparece Ludmilla, cantando, com um aplique cacheado, longo e volumoso. Ao seu redor, diversas mulheres e homens, em sua maioria blogueiros negros famosos nas plataformas digitais, com cabelos encaracolados nos mais variados formatos. A letra, em sintonia com a atmosfera de festa que envolve o videoclipe, ressignifica os sentidos atrelados ao cabelo crespo "Bora definir, deixa enrolar, crespo, poderoso dos seus sonhos vai ficar / Assumo quem eu sou, assumo meu black, agora eu tô de cacho, l'll never go back".

Figura 2: "Agora eu tô de cacho"

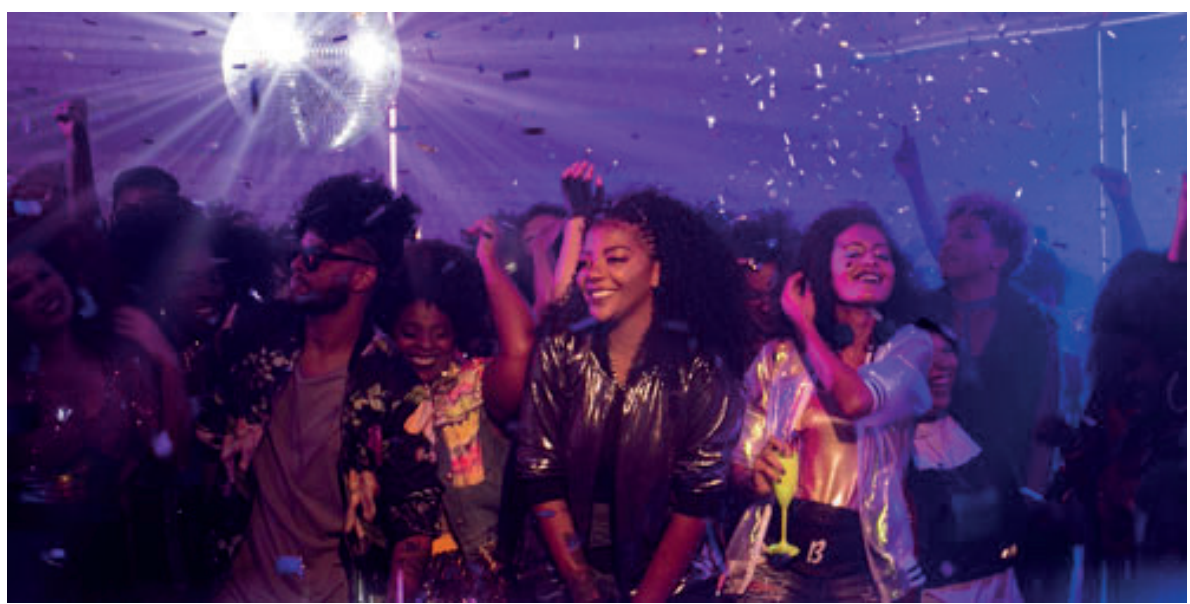

Fonte: <https://revistacabelos.uol.com.br/wp-content/uploads/2017/05/Salon-LineLudmilla-2. jpg $>$.

Nesse sentido, a campanha faz refletir sobre a importância que os veículos e produções midiáticas podem ter na potencialização de discussões acerca de padrões estéticos. Uma pesquisa realizada pela

12 Konrad Cunha Dantas, conhecido pelo nome artístico KondZilla, é um compositor, produtor e empresário brasileiro.

13 Disponível em: <https://www.youtube.com/watch?v=R53wwgxQh5U>. Acesso em: 10 mar. 2020. 
Kantar WorldPanel ${ }^{14}$ mostrou que $51,4 \%$ da população brasileira possui cabelos ondulados, cacheados ou crespos. Contudo, essa diversidade capilar não costuma aparecer em propagandas, comerciais e anúncios publicitários, onde ainda predominam os fios extremamente lisos. Assim, o videoclipe em questão provoca um deslocamento nessa hegemonia, ao visibilizar mulheres fora de um padrão cultuado como o belo, não apenas reconhecendo, mas igualmente celebrando essa diferença.

Em uma sociedade fundamentada em construções sociais que se baseiam na hierarquização da estética, racializada em uma escala valorativa de branquitude, usar o cabelo cacheado ou crespo não é simplesmente uma questão de gosto, mas envolve uma resistência a padrões hegemônicos de beleza e uma tentativa de construir uma identidade que se opõe àquela alicerçada nas normatizações estéticas hegemônicas (ROCHA; GHEIRART, 2016).

Constatamos, assim, como as mídias assumem um caráter descontínuo e contraditório: ao mesmo tempo em que atuam como mantenedoras de tais padrões hegemônicos, possibilitam a criação de espaços de ruptura, brechas por onde a resistência floresce. É com base nessa resistência que emergem as lutas pelo reconhecimento da diferença. Ou seja, ratifica-se sua estrutura medular no que se refere aos embates pelas (re)construções de sentido, viabilizando transformações de ordem sociocultural referentes às corporalidades da mulher negra.

Por fim, mesmo não evidenciando, na maior parte das atuações midiáticas, um engajamento de Ludmilla na abordagem de questões sociais referentes a mulheres negras, podemos perceber que, ao compartilhar suas experiências de transição capilar, a cantora traz visibilidade para temas como a estética negra e suas representações nos espaços midiáticos. Além disso, também estimula uma reflexão sobre como o cabelo se constitui enquanto marcador importante nos sentidos de socialização das mulheres negras.

Relatos presentes em suas narrativas, como, por exemplo, o racismo sofrido na infância por ter um cabelo distante do que era tido como "belo", os processos de alisamento como um esforço em se tornar aceita e a transição capilar entendida como uma forma de resgate de sua identidade étnica, são estratégias utilizadas para problematizar elementos

14 Dados disponíveis em: <https://umw.kantarworldpanel.com/br/Releases/Mercado-de-cabelos-cresce-e-movimenta-R-8-bi-no-Brasil>. Acesso em: 10 jan. 2020. 
vinculados a modelos hegemônicos de beleza. No caso de Ludmilla, verificamos como a estética se transforma em uma possibilidade de negociação de sentidos e a importância da mídia como um lugar onde essas disputas são constantemente travadas.

\section{Considerações finais}

Por meio da análise da campanha publicitária protagonizada pela cantora Ludmilla englobando seu processo de transição capilar, fica patente que os sentidos dos corpos negros são construções sociais intimamente influenciadas por aspectos da cultura e pelas comunicabilidades, com destaque ao papel das mídias. Logo, podemos considerar que as significações provenientes de sua trajetória de transição capilar transcendem o relato individual e ecoam experiências coletivas de racismo e exclusão de muitas outras mulheres negras.

Sendo assim, o caso de Ludmilla pode ser interpretado como um posicionamento político de resistência, inscrito em suas corporalidades. Ao assumir seu cabelo crespo, a consciência da negritude e das relações de poder que abrange, deflagra uma ressignificação de sua própria imagem pública, a reverberar em uma construção identitária que não desconsidera suas origens afrodescendentes. O caráter político do corpo advém incontestável, haja vista que se converte em uma frente de batalha diante de uma conjuntura de racismo estrutural que se arrasta ao longo dos séculos em nosso país (e obviamente em outras partes do mundo).

As lutas por visibilidade, desta maneira, transmutam-se em modos de resistências e re-existência, fomentando embates contra-hegemônicos. O caso Ludmilla é emblemático, mas cabe ressaltar que é a ponta de um grande iceberg: sob as águas da cultura, estereótipos, invisibilidades e depreciação estética continuam a entremear o cotidiano de mulheres e homens negras/os, a demandar contínuos esforços para que haja um ambiente menos opressor aos seus corpos e à plenitude de suas vivências. 


\section{REFERÊNCIAS}

ARAÚJO, Joel Zito. A Força de um desejo: a persistência da branquitude como padrão estético visual. Revista USP, São Paulo, n. 69, p. 72-79, 2006.

ARANTES, Dariane. Celebrando nossos corpos, encrespando nossos fios: a transição capilar como política de visibilidade em narrativas autobiográficas de mulheres negras. 2019. 132 f. Dissertação (Mestrado em Comunicação e Práticas do Consumo) - ESPM, São Paulo, 2019.

BAITELLO, Norval. A serpente, a maçã e o holograma: esboços para uma teoria da mídia. São Paulo: Paulus, 2010.

BRASILEIRO, Yara Brito. Um quilombo na mídia: um estudo discursivo da revista Raça Brasil. 2003. 144 f. Dissertação (Mestrado em Linguística) - Instituto de Estudos da Linguagem, Universidade Estadual de Campinas, Campinas, 2003.

CAMPELO, Cleide Riva. Cal(e)idoscorpos - um estudo semiótico do corpo e seus códigos. São Paulo: Editora: Annablume, 1997.

FERREIRA, Ceiça. Branquitude e regimes de visibilidade no cinema brasileiro: uma análise do filme Orfeu. Comunicação midiática, v. 13, n. 1, p. 78-93, 2018.

GOMES, Nilma Lino. Sem perder a raiz: corpo e cabelo como símbolos da identidade negra. São Paulo: Editora Autêntica, 2007.

HALL, Stuart. Da diáspora. Identidades e mediações. Belo Horizonte: Editora UFMG, 2002.

HOFF, T. M. C. Notas sobre consumo e mercado no Brasil a partir das representações do corpo na publicidade. In: BACCEGA, Maria Aparecida. (Org.). Comunicação e culturas do consumo. São Paulo: Atlas, 2008. p. 166-185.

HOOKS, bell. Alisando nosso cabelo. Portal Geledés, 2014. Disponível em: <https://www.geledes. org.br/alisando-o-nosso-cabelo-por-bell-hooks/>. Acesso em: fev. 2020.

KELLNER, D. A cultura da mídia. São Paulo: Editora Edusc, 2001.

KILOMBA, Grada. Plantation memories. Episodes of everyday racismm. Münster: Verlag, 2010.

NOGUEIRA, I. B. Significações do Corpo Negro. 1998. 143f. Tese (Doutorado em Psicologia Escolar e do Desenvolvimento Humano) - Instituto de Psicologia. São Paulo: Universidade de São Paulo, 1998.

QUINTÃO, A. M. P. O que ela tem na cabeça? Um estudo sobre o cabelo como performance identitária. 2013. 196 f. Dissertação (Mestrado em Antropologia) - Instituto de Ciências Humanas e Filosofia, Universidade Federal Fluminense, 2013.

RINCÓN, Omar. Narrativas mediáticas. O cómo se cuenta la sociedad del entretenimiento. BarceIona: Gedisa. 2006.

ROCHA, Rose de Melo; GHEIRART, Ozzie. "Esse close eu dei!" A pop-lítica "orgunga" de Rico Dalasam. Revista Eco-Pós, v. 19, n. 3, 2016.

ROCHA, Rose de Melo; SILVA, Josimey Costa da; PEREIRA, Simone Luci. Imaginários de uma outra diáspora: consumo, urbanidade e acontecimentos pós-periféricos. Galáxia, n. 30, p. 99-111, 2015. 
SANT'ANNA, Denise Bernuzzi. História da beleza no Brasil. São Paulo: Editora Contexto, 2018.

Data do recebimento: 29 agosto 2019

Data da aprovação: 21 março 2020 


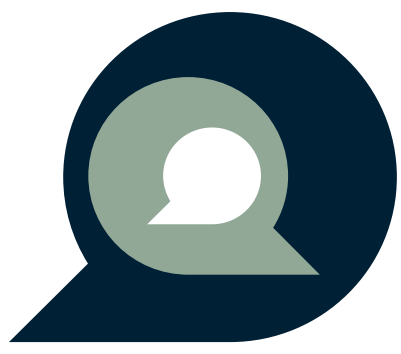

